\title{
Chaetotaxy applied to Norwegian Gyrodactylus salaris Malmberg, 1957 (Monogenea) clades and related species from salmonids
}

\author{
Tor A. Bakke ${ }^{1}$, Kariann B. Nilsen ${ }^{1}$ and Andrew P. Shinn ${ }^{2}$ \\ ${ }^{1}$ Zoological Museum, The Natural History Museums and Botanical Garden, University of Oslo, Oslo, Norway; \\ ${ }^{2}$ Institute of Aquaculture, University of Stirling, Stirling FK9 4LA, Scotland, UK;
}

Key words: Gyrodactylus salaris, parasite, salmonids, taxonomy, chaetotaxy

\begin{abstract}
Gyrodactylus salaris Malmberg, 1957 is a major pathogen of wild Salmo salar L. parr populations in Norway, and its delimitation from non-pathogenic species is important. The present study was undertaken to test the power of chaetotaxy to differentiate between three populations belonging to both the same and different clades (as stated by mtDNA) of G. salaris, in addition to three different species of gyrodactylids ( $G$. salaris, G. thymalli and G. caledoniensis). The gyrodactylids were processed for chaetotaxy in situ and a maximum of 50 specimens per collection site were used to construct a generalised map over the sensilla. The sensilla were found in all populations to be symmetrically distributed around the median longitudinal axis, according to a formula of 7 dorsal ( 34 sensilla) and 8 ventral (44 sensilla) clusters on each side of the median line. The three Norwegian populations of $G$. salaris were found identical, as were the population of $G$. thymalli. The specimens of $G$. caledoniensis from Scotland, however, were found to differ from the Norwegian species G. salaris and G. thymalli by the position of one sensillum in two of the clusters. A comparison of the sensillum pattern of laboratory maintained G. salaris (River Lierelva) with results obtained ten years earlier, questions the temporal stability of the chaetotaxy pattern. The present results indicate that chaetotaxy can be used to discriminate between certain Gyrodactylus spp. but not generally.
\end{abstract}

Species of the monogenean genus Gyrodactylus Nordmann, 1832 are ubiquitous ectoparasites of marine and freshwater teleosts worldwide, and depending on the species, infect fish skin, fins or gills (Bakke and Harris 1998, Bakke et al. 2002). One species, G. salaris Malmberg, 1957, originally described from the Hölle hatchery, Sweden has turned out to be a major pathogen of wild anadromous Atlantic salmon (Salmo salar L.) parr in Norway since its introduction in the mid-seventies (Johnsen and Jensen 1991, Mo 1994, Johnsen et al. 1999). Since 1975, 44 Norwegian rivers have been found to be infected with $G$. salaris, and 28 (December 2003) of them have been treated with rotenone to exterminate the hosts and, subsequently, the parasite (Mo et al. 2004).

A recent molecular genetic study based on mtDNA mitochondrial cytochrome oxidase I gene (CO1) demonstrated that at least three clades of $G$. salaris have been introduced into Norway by man, most probably from infected hatcheries located around the Baltic Sea (Hansen et al. 2003). Further distribution within Norway is believed to be through the movement of salmon parr and smolts used for restocking of rivers (Johnsen and Jensen 1986, Johnsen et al. 1999), and through natural brackish water dispersal through fiord systems (Lund and Heggberget 1992, Soleng et al. 1998, Johnsen et al. 1999).

Approximately 400 Gyrodactylus species have been described, 29 species of which are recorded on salmonids worldwide (Bakke et al. 2002). Traditionally, species of Gyrodactylus are identified on the basis of subtle differences in the shape and size of the opisthaptoral sclerites (Mo 1991a, b, c, Shinn et al. 2000, 2001), the phenotype of which may be dependent on environmental factors such as temperature (Mo 1991a, c). Based on the excretory system, anchors and ventral bars, Malmberg $(1970,1993)$ divided the Gyrodactylus species into subgenera and species-groups, respectively. Malmberg also separated from the wagenerigroup a $G$. salaris-group which he further divided into three subgroups of which $G$. salaris and $G$. thymalli Žitnaan, 1960 belong to two of the subgroups. The recently described $G$. caledoniensis Shinn, Sommerville et Gibson, 1995 from salmon and rainbow trout in UK belongs to Malmberg's G. wageneri-group (A. Shinn, unpubl. observations). Later, however, based on molecular genetics, Cable et al. (1999) compared Malmberg's (1970) phylogeny of the genus and found no support that $G$. salaris is a member of a separate species-group as it clustered within the $G$. wageneri-group which could be further subdivided into groups with different host preferences. In addition, Matějusová et al. (2003) suggested that the existing subgenera should be abandoned as the excretory system seems not to be conservative enough to reveal subgenera.

Several studies have used the silver nitrate staining technique of Lynch (1933) to describe the sensory sensilla in both larval (Combes and Lambert 1975, Lambert 1977a, b, 1978a, b, Tinsley 1978) and adult monogeneans (Lambert 1979, El-Naggar et al. 1993, 2001, Khidr

This paper was presented at the 6th International Symposium on Fish Parasites in Bloemfontein, South Africa, 22-26 September 2003. 
and El-Naggar 1996). Chaetotaxy has also been used to examine the phylogenetic position of Gyrodactylus within the Monogenea (Shinn et al. 1998a). Shinn et al. (1997, 1998b) applied chaetotaxy to differentiate Gyrodactylus species belonging to the $G$. wageneri-group parasitizing British salmonids besides two G. salaris populations (Swedish River Ätran and Norwegian River Lierelva), and proposed a formula for the arrangement of the natural aggregations of sensilla. They concluded that chaetotaxy had potential as a relatively simple and reliable method for distinguishing species of the genus.

In a molecular genetic study based on mtDNA (CO1) sequences from G. salaris and G. thymalli populations in Norway and Sweden (Hansen et al. 2003), it was shown that these species could be separated into three and two clades, respectively. Each clade was found to be unique in having a different invasion history and pathogenesis to salmon (Bakke et al. 2002, Sterud et al. 2002). Hence, there is an urgent need to find morphological markers which can readily separate specimens into their respective species and clades. The present study aims to investigate the use of chaetotaxy to differentiate between $G$. salaris populations (on Atlantic salmon) and $G$. thymalli (on Thymallus thymallus L.) representing different clades and species-groups, and $G$. caledoniensis on $S$. salar, River Allan, representing a different subgroup.

\section{MATERIALS AND METHODS}

Specimens of Gyrodactylus salaris were collected from infected Atlantic salmon (Salmo salar) parr sampled by electrofishing in three different Norwegian localities: Rivers Lierelva and Drammenselva, Buskerud County, and River Rauma, Møre and Romsdal County. G. salaris-infected parr (infected fins from the River Rauma) were transported to the Zoological Museum (ZM), University of Oslo, and transferred by exposure to naïve salmon parr (Lierelva stock). G. thymalli were collected from infected grayling (Thymallus thymallus) sampled by rod fishing in the River Rena, Hedmark County, transported live to the $\mathrm{ZM}$ and transferred by exposure to naïve grayling (Rena stock). G. caledoniensis were collected by electrofishing Atlantic salmon parr in the River Allan, Scotland, and transported live in situ to the aquarium unit at the Institute of Aquaculture (IA), University of Stirling (Table 1).

The fish with the three Norwegian strains of $G$. salaris, and those with $G$. thymalli, were kept in separate tanks and boxes with a wire mesh bottom, floating within a larger tank, respectively. The Norwegian populations were supplied with charcoal-filtered, de-chlorinated water adjusted to ca. $10-12^{\circ} \mathrm{C}$. The G. caledoniensis-infected salmon were kept in tanks supplied with water from the River Allan adjusted to ca. $10^{\circ} \mathrm{C}$.

Infected fish examined for gyrodactylids after being anaesthetized with $0.04 \%$ chlorobutanol for ca. 2 min were killed and fins with Gyrodactylus spp. were excised and washed in $2.0 \mathrm{M}$ phosphate buffer $\left(\mathrm{Na}_{2} \mathrm{HPO}_{4} \cdot 12 \mathrm{H}_{2} \mathrm{O}+\mathrm{Na}_{2} \mathrm{HPO}_{4} \cdot 2 \mathrm{H}_{2} \mathrm{O}\right)$ at $\mathrm{pH} 7.2$ to remove excess mucus prior to staining. The gyrodactylids were processed for chaetotaxy in situ on the fins: the infected fins were placed directly into $2.0 \%$ silver nitrate $\left(\mathrm{AgNO}_{3}\right)$ at $65-70^{\circ} \mathrm{C}$ in the dark for 5 min (modified from Shinn et al. 1997, 1998b). Afterwards, the fins were carefully washed in 5-10 changes of distilled water. The fins were then submerged in distilled water and each side of the fin exposed to UV light $(325 \mathrm{~nm})$ for $5 \mathrm{~min}$. After UV exposure, the fins were again washed to remove any host mucus (which takes up silver stain) before being transferred to a solution of $10 \%$ glycerine and $90 \%$ ethanol. The ethanol was allowed to evaporate, leaving the fins in glycerine. Only gyrodactylids with an empty uterus were selected and mounted in glycerine on a glass slide. Glycerine as a mountant made it possible to manipulate the parasite into a position for mapping each sensillum and to maximise the number of sensilla visible in any focal plane. Precautions were taken not to displace sensilla through excessive coverslip pressure when rolling. The slides were stored in the dark in a refrigerator at $4{ }^{\circ} \mathrm{C}$.

For scanning electron microscopy (SEM), fins were fixed for $24 \mathrm{~h}$ at $4{ }^{\circ} \mathrm{C}$ in $2.0 \%$ glutaraldehyde buffered to $\mathrm{pH} 7.4$ with $0.1 \mathrm{M}$ sodium cacodylate buffer, post-fixed in $1-2 \%$ osmium tetroxide $\left(\mathrm{OsO}_{4}\right)$ for $1 \mathrm{~h}$ at $20^{\circ} \mathrm{C}$. Subsequently, the fins were dehydrated through a graded ethanol series and dried in a Balzer critical-point-dryer using liquid $\mathrm{CO}_{2}$, mounted on aluminium stubs and sputter coated (Polaron) with gold-palladium and examined in a JEOL JSM 6400 scanning electron microscope, operating at $10 \mathrm{kV}$. Parasites fixed for transmission electron micoscopy (TEM) were individually fixed overnight in $2 \%$ glutaraldehyde in $0.1 \mathrm{M}$ sodium cacodylate buffer, $\mathrm{pH} 7.4$, at $4^{\circ} \mathrm{C}$. Thereafter, the specimens were rinsed in the same buffer ( 2 changes of $10 \mathrm{~min}$ each) at room temperature and post-fixed in $1 \%$ osmium tetroxide with $1.5 \%$ potassium ferricyanide (Sigma) for $1 \mathrm{~h}$ in the dark. The specimens were then rinsed 5 times in distilled water $(10 \mathrm{~min})$ before being stained in $1.5 \%$ uranyl acetate (Merck) in distilled water for 30 min in the dark. Following dehydration in ethanol, the parasites were placed in propylene oxide (Fluka) ( 2 changes of 10 min each) and infiltrated in Epon 812 resin (Fluka) overnight

Table 1. A summary of the Gyrodactylus species, populations and numbers analysed by chaetotaxy (number examined: dorsal surface, right/left sides - ventral surface, right/left sides).

\begin{tabular}{|l|l|l|l|}
\hline \multicolumn{1}{|c|}{ Parasite species } & \multicolumn{1}{|c|}{$\begin{array}{c}\text { Number } \\
\text { examined }\end{array}$} & \multicolumn{1}{|c|}{ Host species } & \multicolumn{1}{c|}{ River localities } \\
\hline G. salaris Malmberg, 1957 & $45 / 49-50 / 50$ & Salmo salar & Lierelva, Buskerud County, Norway \\
G. salaris Malmberg, 1957 & $17 / 16-9 / 8$ & Salmo salar & Drammenselva, Buskerud County, Norway \\
G. salaris Malmberg, 1957 & $48 / 48-47 / 47$ & Salmo salar & Rauma, Møre and Romsdal County, Norway \\
G. thymalli Žitñan, 1960 & $18 / 15-13 / 8$ & Thymallus thymallus & Rena, Hedmark County, Norway \\
$\begin{array}{l}\text { G. caledoniensis } \\
\text { Shinn, Sommerville et Gibson, 1995 }\end{array}$ & $32 / 31-31 / 30$ & Salmo salar & Allan, Perthshire, Scotland \\
\hline
\end{tabular}


before embedding in the resin. The blocks were sectioned using a Sorvall MT5000 ultramicrotome, stained with Reynolds lead citrate $(0.1 \mathrm{~g}$ in $50 \mathrm{ml} 0.1 \mathrm{~N} \mathrm{NaOH})$ and examined in a Phillips CM100 transmission electron microscope.

The chaetotaxy maps for the dorsal and ventral surfaces of each population were drawn by a drawing tube using a Leitz microscope $(1000 \times)$ and based on up to 50 stained and mounted specimens (Table 1). Due to the symmetric distribution of sensilla about the longitudinal axis, only the right side was used in the analyses. The designation of clusters was based on a visual assessment of the aggregation of sensilla. These clusters are referred to as being either on the dorsal (D) or ventral $(\mathrm{V})$ surface, and belonging to one of the main areas: (i) anterior - three cluster positions on DA and VA; (ii) body proper - three cluster positions on $\mathrm{DB}$, four on $\mathrm{VB}$; and (iii) opisthaptor - one cluster position on DO and VO. Within each cluster, the sensilla are coded in an anterior to posterior direction following the lines as shown on the generalised map in Fig. 5. From the first usable maps a species-specific map was derived which was then used to compare against the remaining specimens. Any incongruence observed to the general pattern of each population was noted.

To confirm the identity of the gyrodactylids, silver nitratestained parasites from each locality were digested with proteinase $\mathrm{K}$ according to the method of Harris et al. (1999), mounted in ammonium picrate glycerine according to Malmberg (1970) and compared by use of a phase-contrast microscope $(400-1000 \times)$ with the original species descriptions of each species.

\section{RESULTS}

The greatest concentration of sensilla was observed on the cephalic lobes in the vicinity of the two relatively large and tapering spike sensilla (Figs. 1, 2). In addition, there appear to occur at least three other types of sensilla based on their external morphology: relatively short sensilla with a distal bulb (club sensilla), and sensilla of a variable length of which one type taper towards their distal tip (tapering sensilla) while the other does not (common body sensilla). The latter were most commonly encountered by SEM on the body proper and are assumed to dominate the chaetotaxy maps. Occasionally, holes in the tegument were observed which may indicate lost sensilla (Fig. 2). Fig. 3 demonstrates the penetration of the tegument by a body sensillum and its nervous innervation as seen by TEM. Sensilla stained with silver nitrate appear as dark rings when viewed by light microscope, probably due to staining of the nerve process around the sensilla on penetration of the tegument (Fig. 3). Generally, several specimens were required to construct the sensillum pattern, as occasionally some sensilla for whatever reason failed to stain or only produced a weak reaction (see Fig. 4). Silver nitrate infiltrated into the oral opening, the excretory pores and the openings through which the opisthaptoral hooks emerge from the tegument. These stained areas may serve as useful landmarks in the identification of a specific sensillum or clusters (Fig. 4).
Two regions with sensilla that were found to be unreliable were omitted from further analyses: (i) the area around the cephalic lobes (the rounded shape and high concentration of sensilla made a rigorous assessment of the number and position of sensilla difficult); (ii) the lateral area (the dorso-ventral compression made the precise number and position of sensilla on the lateral margins difficult to assess). In addition, the opisthaptor had a tendency to twist as the specimen was rolled into the correct orientation. This made the assessment of the number of sensilla and the definition of their position on the opisthaptor difficult to define (even if only one sensillum cluster was defined) (Fig. 5). Also, the infiltration of silver nitrate into the openings of the marginal hook could easily be mistaken for sensilla. All remaining sensilla, however, showed a consistent bi-lateral symmetrical pattern around the longitudinal median axis with the highest density of sensilla being in the circumoral and opisthaptoral peduncle regions.

The sensilla could be grouped into clusters consisting of between three to ten sensilla (Fig. 5). However, a relatively large variation was observed in occurrence of the individual sensilla within the clusters in the populations. The frequency of occurrence of each stained sensillum was determined for each population. Only sensilla that were stained with a frequency $\geq 70 \%$ were used for the subsequent comparisons. Any displacement of these sensilla observed was determined. The River Rauma population had the highest level of displaced sensilla (1.6\%) compared to the populations of $G$. salaris from the Rivers Lierelva and Drammenselva ( $1.1 \%$ and $0.9 \%$, respectively). In $G$. thymalli specimens, the percentage displacement was $0.9 \%$. The displacement of sensilla, in each population, was evenly dispersed throughout the clusters.

The analyses of the five populations of Gyrodactylus revealed that the number of sensilla within each of the defined clusters on the dorsal and ventral side for each species was the same (Table 2). There were 34 sensilla grouped into 7 clusters on the dorsal surface. The dorsal-anterior region comprised three clusters (DA1DA3) of 5, 4 and 5 sensilla, respectively, the latter cluster of 5 sensilla (DA3) being situated close to the excretory pore (Fig. 5). The remaining dorsal-body clusters (DB1-DB3) were found to have a consistent number of 4, 4 and 8 sensilla, respectively. Ventrally, all populations had a total of 44 sensilla grouped into 8 clusters (Table 2). The ventral-anterior region harbours three clusters (VA1-VA3) of 4, 10 and 7 sensilla, respectively. The first cluster (VA1) is situated mediolaterally in close proximity to the anterior lobes, whilst the VA2 cluster which possesses the largest number of sensilla is situated towards the lateral margins. The third cluster (VA3) is composed of seven sensilla in a characteristic zigzag pattern close to the median axis (at approximately the same longitudinal position as the VA2 cluster) with 5 sensilla anterior and 2 sensilla posterior 


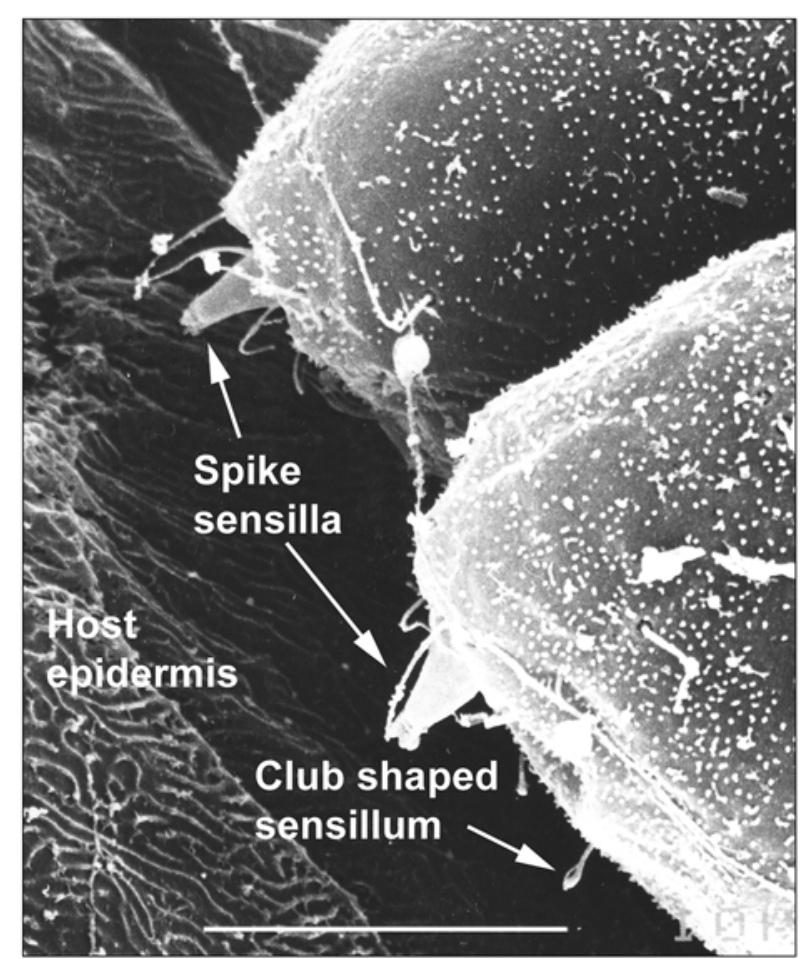

Fig. 1. Scanning electron micrograph (SEM) of the cephalic lobes of Gyrodactylus salaris in close proximity to the epidermis of its host, an Atlantic salmon (Salmo salar). The picture highlights the concentration of sensilla within the region. Two types of sensilla can be seen: the spike sensilla and the clubshaped sensilla. Scale bar $=10 \mu \mathrm{m}$.

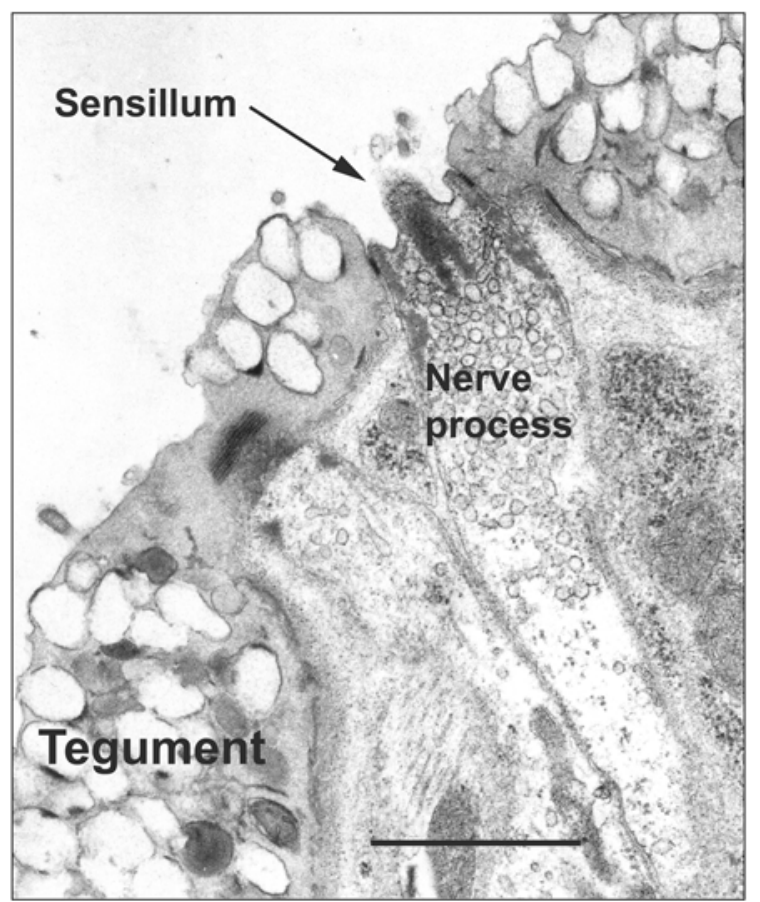

Fig. 3. Transmission electron micrograph (TEM) showing a cross-section through a sensillum and its innervation within the tegument of Gyrodactylus salaris. Scale bar $=1 \mu \mathrm{m}$.

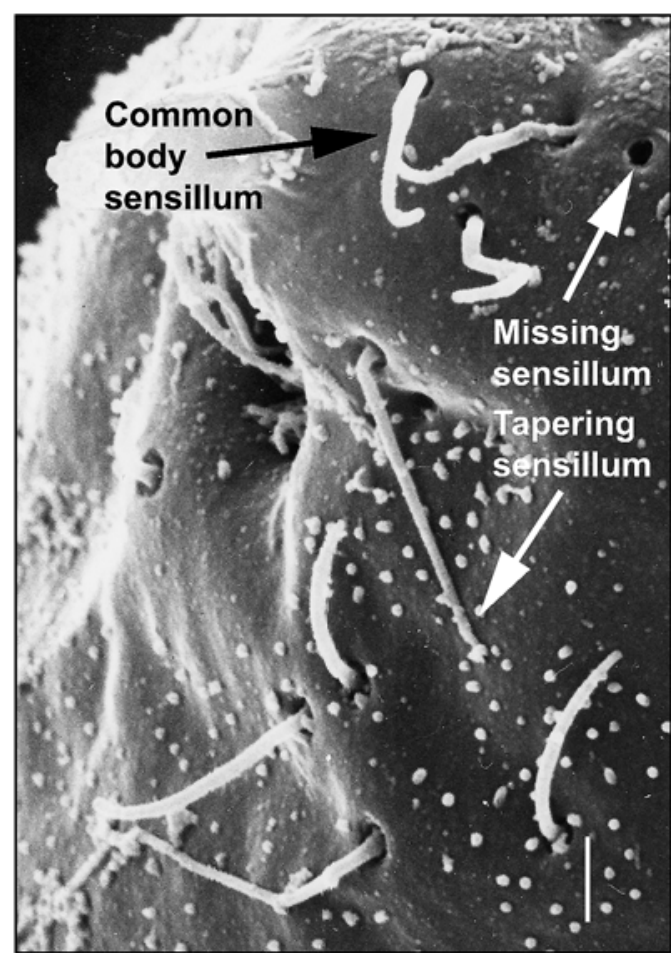

Fig. 2. Scanning electron micrograph (SEM) of the sensilla at the anterior end of Gyrodactylus salaris demonstrating two other types of sensilla (see Fig. 1): the tapering and the common body sensilla. Scale bar $=1 \mu \mathrm{m}$.

to the oral pore (Fig. 5). The remaining four clusters (VB1-VB4) on the ventral surface have 5, 3, 8 and 4 sensilla, respectively. The second cluster (VB2) of three sensilla showed a characteristic pattern in line in the middle close to the longitudinal axis of the worm. The posterior-most cluster (VB4) is situated close to the peduncle of the body proper. The sensilla on the ventral side of the opisthaptor were difficult to map for the reasons already stated, however, when the sensilla were discernible, a set of two sensilla situated on the posterior edge of the opisthaptor and one anterior-lateral sensillum, could be observed (Fig. 5).

The general chaetotaxy map produced from stained specimens of $G$. salaris was used as the standard by which the other $G$. salaris populations were compared (Fig. 5). No significant differences in the chaetotaxy pattern were observed between the populations of $G$. salaris (Table 2, Fig. 5). However, a higher percentage of sensilla on $G$. salaris specimens from the River Rauma population were observed to be duplicated or displaced. Specimens from the Lierelva population were only occasionally observed to have a displaced sensillum, and when it was seen it was usually towards the lateral margins (e.g. sensillum 1 in DA3 and sensillum 4 in DB1; see Fig. 5).

The specimens of $G$. thymalli had the same number of sensilla and a similar chaetotaxy pattern to that observed on the G. salaris specimens. No significant 


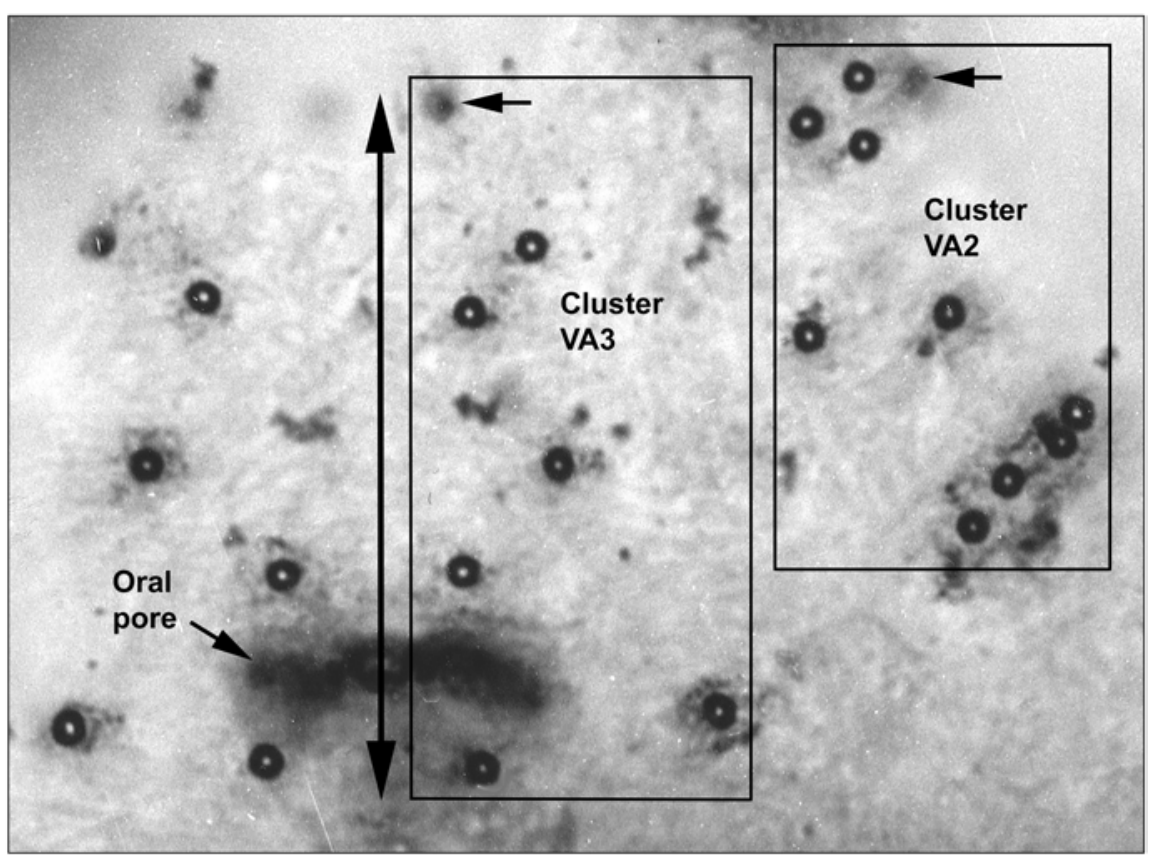

Fig. 4. Light micrograph (LM) displaying the distribution of sensilla around the oral aperture of Gyrodactylus salaris from River Lierelva, Norway. The sensilla, when stained with silver nitrate, appear as black structures with a symmetrical distribution along the longitudinal axis of the worm (long arrow). The rectangles indicate the sensilla belonging to the VA2 and VA 3 clusters. The small arrows point to sensilla within the respective clusters that are out of focal range or are poorly stained as also occasionally observed. Scale bar $=5 \mu \mathrm{m}$

differences were registered between these clades representing two different species. Specimens of G. caledoniensis likewise had the same number and a similar arrangement of the ventral sensilla as G. salaris (Table 2, Fig. 5). However, two significant differences were recognized on the dorsal surface (Fig. 6, shaded regions): in cluster DB2, the two most medially positioned sensilla have a reverse configuration, and in cluster DB3 the distance between the 5th and 6th sensilla is consistently shorter than that observed in the $G$. salaris specimens.

\section{DISCUSSION}

The definition of sensillum clusters was assigned after visual assessment of the sensillum arrangements after staining and, therefore, may not correspond with the underlying branching structure of the nerve system. Shinn et al. (1997) suggested that the ventro-median cluster of $3 \times 2$ sensilla mirrored the $3 \times 2$ perikarya of the dorsal nerve cords that Reuter (1987) stained with the antisera to FMRF-amide in a study of neuroactive substances in $G$. salaris. The sensilla are obviously innervated as shown in the present study, but the sensillum associations with the underlying nervous system and its commissures remain to be established on gyrodactylids. SEM observations on $G$. salaris revealed the presence of different types of sensilla, which suggests that each type has a different function responding to either physical or chemical stimuli. It is interesting to note that the sensilla on the dorsal surface have a more even distribution than on the ventral surface. The high number of sensilla distributed ventrally around the oral pore and the region of the penis probably indicates that the sensilla serve to orientate the gyrodactylid during feeding and copulation. These sensilla may in all likelihood have a different function to those sensilla distributed around the cephalic lobes, which must play a crucial role when transmitting between hosts and moving over the host's epidermis. In addition to the sensillum types mentioned here, Watson and Rohde (1994) found two other receptors which they suggested might be light sensitive, but not linked to any external structures.

A variety of approaches have been used to identify and discriminate different species of Gyrodactylus. Such studies have included the use of morphology using light (e.g. Malmberg 1970, Shinn et al. 1995) and scanning electron microscopy (e.g. Mo and Appleby 1990, Shinn et al. 1993), molecular-based methodologies (e.g. Cunningham et al. 1995a, b, Sterud et al. 2002, Zietara and Lumme 2002, Hansen et al. 2003), and ecological data such as host preferences (e.g. Malmberg 1970, see Bakke et al. 2002). Concerning chaetotaxy, the sensillum pattern is supposed to remain consistent throughout life because of the almost mature progeny when born. Based on this premise, Shinn et al. (1997, 1998a, b) assessed for the utility of chaetotaxy in gyrodactylid sys- 

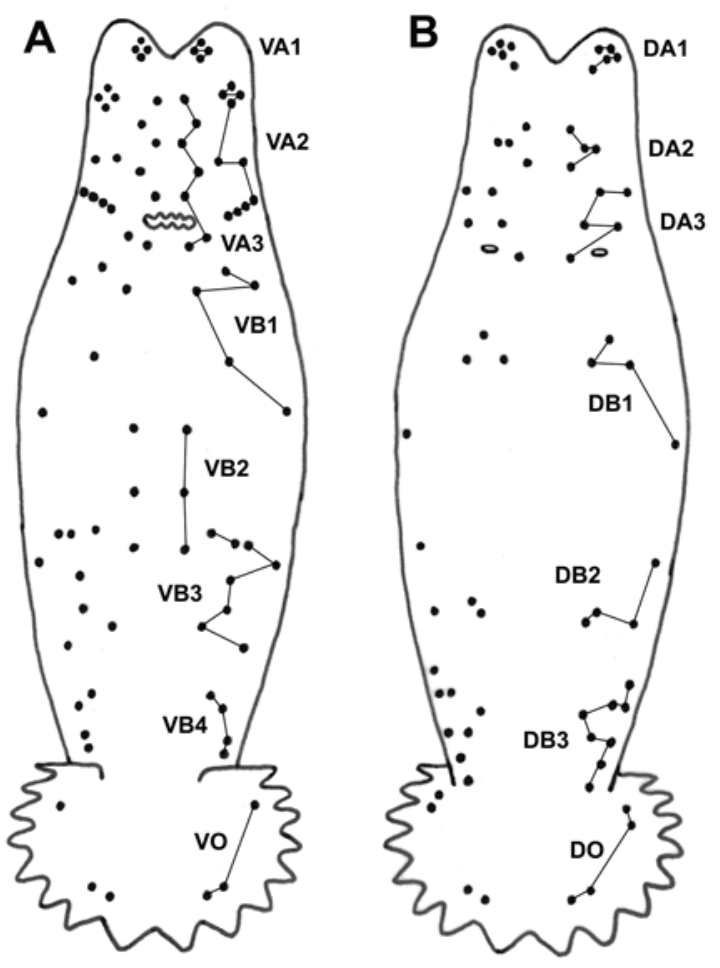

Fig. 5. Chaetotaxy map illustrating the distribution and approximate organisation of each coded cluster of sensilla on a generalised Gyrodactylus sp. infecting Norwegian salmon and grayling. The sensilla within each cluster are linked with lines for clarity. A - ventral side; B - dorsal side. (See Table 2 for abbreviations.)

tematics. Generally, within the Monogenea, chaetotaxy had previously been applied to a number of genera but with a greater emphasis on the study of larval forms than adult worms (e.g. within polystomids, diplozoids, ancyrocephalids, capsalids, and cichlidogyrids).

In the present study, displaced, missing or duplicated sensilla were observed in all of the studied populations of Gyrodactylus. Generally, displacement and duplications occurred most frequently among the G. salaris specimens from the River Rauma, which accordingly exhibited the greatest variability among the populations. The Rauma material was prepared directly from wildcaught fish, whilst the specimens from the Rivers Drammenselva and Lierelva were taken from cultivated stocks that were maintained in the laboratory and, therefore, could be more homogeneous. Despite this variation, by using a large number of specimens, it was possible to produce a generalised sensillum map for each population.

By sequencing the mtDNA CO1 gene, Hansen et al. (2003) determined that the population of G. salaris from the Rivers Lierelva and Drammenselva belonged to the same clade, whilst $G$. salaris from the River Rauma represented another clade, as did sequenced specimens of G. thymalli from the River Rena. In the current study
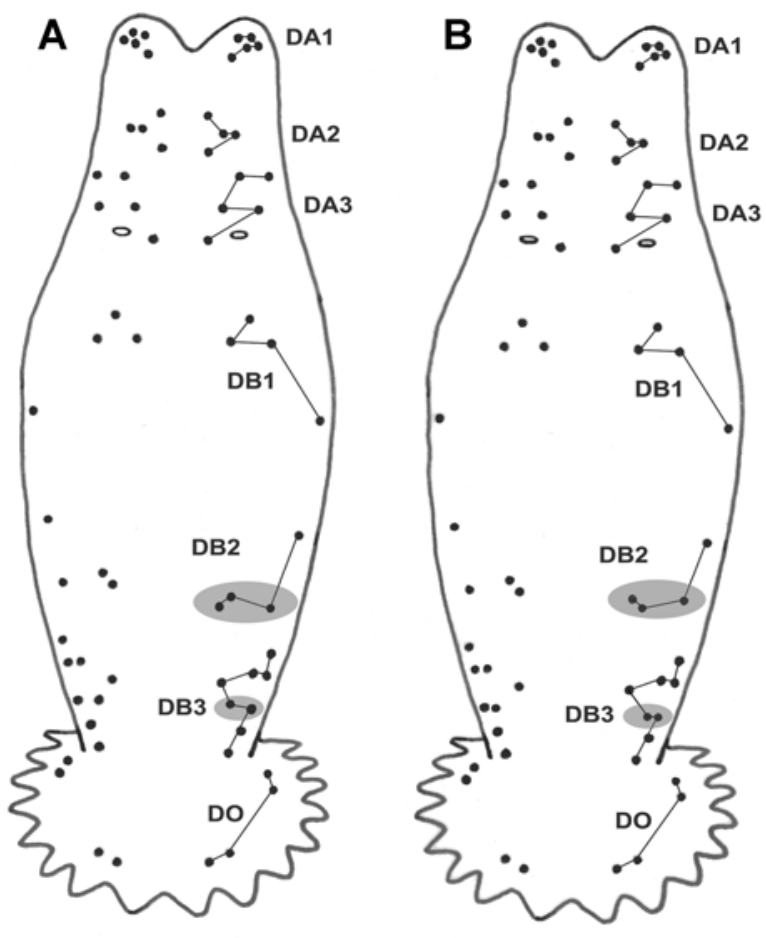

Fig. 6. Chaetotaxy maps showing the difference in arrangement of sensilla within clusters DB2 (shaded area) and DB3 (shaded area). A - Gyrodactylus salaris from the River Lierelva; B - G. caledoniensis from the River Allan, Scotland.

using chaetotaxy, however, no significant differences were observed between G. salaris and G. thymalli. This similarity supports the morphological (Žitňan 1960, Ergens 1983, Malmberg 1993, Mo 1994, Denham and Long 1999) and genetic (Cunningham et al. 1995b, Zietara and Lumme 2002) similarities reported. However, G. thymalli has a restricted reproduction on salmon (Soleng and Bakke 2001, Bakke et al. 2002, Sterud et al. 2002), and Shinn et al. (2000, 2004), using morphology, were able to differentiate $G$. thymalli from $G$. salaris, as was Sterud et al. (2002) by sequencing the intergenic spacer region (IGS). Of the five populations under study, only the chaetotaxy pattern of G. caledoniensis could be discriminated from the others, but only based on the position of a single sensillum in two different clusters on the dorsal surface. Both the number and pattern of sensilla were remarkably similar in these three Gyrodactylus species infecting salmonids. With this in mind, Shinn et al.'s (1998b) observation that a Norwegian G. salaris population (River Lierelva) could be differentiated from a Swedish population (River Ätran, west coast of Sweden), which occupies another clade (Hansen et al. 2003), is particularly interesting. The present study, however, suggests that chaetotaxy is not generally applicable for the discrimination of gyrodactylids occupying different, but closely related clades. 
Table 2. The number of sensilla recorded within each cluster. Only the numbers for the right side are presented as the sensilla are symmetrically distributed along the longitudinal axis of the worm (see Fig. 4-6). The three Gyrodactylus salaris populations, and G. thymalli and G. caledoniensis had the same numbers of sensilla within each cluster. Cluster acronyms: DA, dorsal anterior; DB, dorsal body; DO, dorsal opisthaptor; VA, ventral anterior; VB, ventral body; VO, ventral opisthaptor (see Fig. 5.)

\begin{tabular}{|c|c|c|c|}
\hline \multicolumn{2}{|c|}{ Dorsal } & \multicolumn{2}{c|}{ Ventral } \\
\hline Clusters & $\begin{array}{c}\text { Number } \\
\text { sensilla }\end{array}$ & Clusters & $\begin{array}{c}\text { Number } \\
\text { sensilla }\end{array}$ \\
\hline DA1 & 5 & VA1 & 4 \\
DA2 & 4 & VA2 & 10 \\
DA3 & 5 & VA3 & 7 \\
DB1 & 4 & VB1 & 5 \\
DB2 & 4 & VB2 & 3 \\
DB3 & 8 & VB3 & 8 \\
& & VB4 & 4 \\
DPH1 & 4 & VPH1 & 3 \\
\hline Total & 34 & & 44 \\
\hline
\end{tabular}

Shinn et al. (1997) observed two different types of sensilla on silver nitrate-stained gyrodactylid specimens, one large dark type that conformed to a pattern symmetrical along the median longitudinal axis, and a second smaller, randomly distributed type that was not included in the chaetotaxy formulae. In the present study, only the sensilla which appeared as dark rings were mapped. These sensilla were in general agreement with those mapped by Shinn et al. (1997, 1998a, b) which had an occurrence $\geq 70 \%$. However, the present defined clusters and coding of sensilla differ from the previous system but attempt to increase the utility of chaetotaxy as a diagnostic method. Shinn et al. (1998b) observed a total of 154 sensilla on G. salaris from the River Lierelva (36 dorsally, 41 ventrally, on one side), the current study by comparison found a total of 156 sensilla (34 dorsally, 44 ventrally). Besides, some discrepancies in the position of certain sensilla were noted. The present study has shown that the arrangement of sensilla in the posterodorsal clusters (DB2 and DB3) is the key to separate the present species of Gyrodactylus. In contrast, Shinn et al. (1997) concluded that it was the pattern of sensilla posterior to the pharynx in the anteroventral and mediolateral clusters, that were the most informative in permitting the discrimination of the Gyrodactylus species mapped. These differences between studies, in part, arise from the designation of clusters and coding of sensilla. However, differences resulting from natural changes within the Lierelva population over time cannot be excluded (studies performed 10 years apart). In addition, the results may highlight problems when comparing laboratory isolated strains to wild-caught populations.

In the present study, the Norwegian gyrodactylids of different clades and species-groups from Atlantic salmon and grayling were found to be identical, but $G$. caledoniensis from Scotland differed from $G$. salaris and G. thymalli by the position of two sensilla (in clusters DB2 and DB3). The results confirm the potential of using chaetotaxy in gyrodactylids to discriminate between certain species of Gyrodactylus but not generally. The temporal stability of the chaetotaxy patterns of specific gyrocatylids needs to be determined.

Acknowledgements. We want to thank Ove Eide at "Fylkesmannen i Møre og Romsdal" County for supplying samples from the River Rauma, Trond Håvelsen at "Drammen og Omegns Fiskeradministrasjon" (DOFA) for the supply of hatchery-reared naïve salmon, Toril $\mathrm{M}$. Rolfsen and Tove Bakar, University of Oslo, for help at the Electron Microscopy Unit for Biological Studies, and Kjersti Kvalsvik, The Natural History Museums and Botanical Garden, University of Oslo, for help with the fish stocks at the Zoological Museum. A short study visit by Kariann B. Nilsen to Scotland was supported through an award to Tor A. Bakke from the European Union Access to Research Infrastructures (ARI) Action of the Improving Human Potential (IHP) Programme (contract HPRI-CT-1999-00106). The project was supported by a grant from the Norwegian Research Council (Project no. 145861/ 720).

\section{REFERENCES}

BAKKE T.A., HARRIS P.D. 1998: Diseases and parasites in wild Atlantic salmon (Salmo salar) populations. Can. J. Fish. Aquat. Sci. 55 (Suppl. 1): 247-266.

BAKKE T.A., HARRIS P.D., CABLE J. 2002: Host-specificity dynamics: observations on gyrodactylid monogeneans. Int. J. Parasitol. 32: 281-308.

CABLE J., HARRIS P.D., TINSLEY R.C., LAZARUS C.M. 1999: Phylogenetic analysis of Gyrodactylus spp. (Platyhelminthes: Monogenea) using rDNA sequences. Can. J. Zool. 77: 1323-1331.

COMBES C., LAMBERT A. 1975: La chétotaxie des larves nageantes de Polystomes européens (Monogenea). Ann. Parasitol. Hum. Comp. 50: 25-37.
CUNNINGHAM C.O., McGILLIVRAY D.M., MacKENZIE K., MELVIN W.T. 1995a: Identification of Gyrodactylus (Monogenea) species parasitizing salmonid fish using DNA probes. J. Fish Dis. 18: 539-544.

CUNNINGHAM C.O., McGILLIVRAY D.M., MacKENZIE K., MELVIN W.T. 1995b: Discrimination between Gyrodactylus salaris, G. derjavini and G. truttae (Platyhelminthes: Monogenea) using restriction fragment length polymorphisms and an oligonucleotide probe within the small subunit ribosomal RNA gene. Parasitology 111: 8794.

DENHAM K.L., LONG J. 1999: Occurrence of Gyrodactylus thymalli Žitňan, 1960 on grayling, Thymallus thymallus (L.), in England. J. Fish Dis. 22: 247-252. 
El-NAGGAR M.M., ARAFA S.Z., El-ABASSAY S.A., KEARN G.C. 2001: Chaetotaxy of the monogeneans Macrogyrodactylus clarii and M. congolensis from the gills and skin of the catfish Clarias gariepinus in Egypt, with a note on argentophilic elements in the nervous system. Folia Parasitol. 48: 201-208.

El-NAGGAR M.M., REDA E.S., ARAFA S.Z. 1993: Observations on the anatomy and surface sensilla of Pseudodactylogyrus anguillae (Yin and Sproston, 1948) Gussev, 1965, a monogenean gill parasite of Anguilla anguilla in Egypt. J. Egypt. Ger. Soc. Zool. 11 (D): 147-175.

ERGENS R. 1983: Gyrodactylus from Eurasian freshwater Salmonidae and Thymallidae. Folia Parasitol. 30: 15-26.

HANSEN H., BACHMANN L., BAKKE T.A. 2003: Mitochondrial DNA variation of Gyrodactylus spp. (Monogenea, Gyrodactylidae) populations infecting Atlantic salmon, grayling and rainbow trout in Norway and Sweden. Int. J. Parasitol. 33: 1471-1478.

HARRIS P.D., CABLE J., TINSLEY R.C., LAZARUS C.M. 1999: Combined ribosomal DNA and morphological analysis of individual gyrodactylid monogeneans. J. Parasitol. 85: 188-191.

JOHNSEN B.O., JENSEN A.J. 1986: Infestations of Atlantic salmon, Salmo salar, by Gyrodactylus salaris in Norwegian rivers. J. Fish Biol. 26: 233-241.

JOHNSEN B.O., JENSEN A.J. 1991: The Gyrodactylus story in Norway. Aquaculture 98: 289-302.

JOHNSEN B.O., MØKKELGJERD P.I., JENSEN A.J. 1999: The parasite Gyrodactylus salaris on salmon parr in Norwegian rivers, status report at the beginning of year 2000. NINA Oppdargsmelding 617: 1-129. (In Norwegian, English summary.)

KHIDR A.A., El-NAGGAR M.M. 1996: Observations on the anatomy and surface sensilla of the monogenean gill parasite Cichlidogyrus arthracanthus Paperna, 1960 from Tilapia spp. in Egypt. J. Egypt. Ger. Soc. Zool. 19 (D): 21-41.

LAMBERT A. 1977a: Développement larvaire et post-larvaire d'Ergenstrema mugilis Paperna, 1964 (Monogène, Ancyrocephalidae) parasite de Liza ramada (Risso, 1826) (Téléostéen, Mugilidae). Z. Parasitenkd. 52: 229-240.

LAMBERT A. 1977b: L'oncomiracidium d'Ancyrocephalus paradoxus Creplin, 1839 (Monogenea, Monopisthocotylea) parasite de Sander lucioperca (Téléostéen, Percidae). Ann. Parasitol. Hum. Comp. 52: 493-505.

LAMBERT A. 1978a: Précisions sur l'oncomiracidium de Tetraonchus monenteron (Wagener, 1857) Diesing, 1858 (Monogenea, Tetraonchidae) parasite d'Esox lucius L. (Téléostéen). Ann. Parasitol. Hum. Comp. 53: 117-121.

LAMBERT A. 1978b: Recherches sur l'oncomiracidium des Capsalidae (Monogenea). Ann. Parasitol. Hum. Comp. 53: 351-357.

LAMBERT A. 1979: Recherches sur les affinités phylétique des vers parasites Gyrodactylidae (Monogenea). C. R. Acad. Sci. Paris 288 (D): 231-233.

LUND R.A., HEGGBERGET T.G. 1992: Migration of Atlantic salmon, Salmo salar L., parr through a Norwegian fjord: potential infection path of Gyrodactylus salaris. Aquacult. Fish. Manag. 23: 367-372.
LYNCH J.E. 1933: The miracidium of Heronimus chelydrae MacCallum. Q. J. Microsc. Sci. 76: 13-33.

MALMBERG G. 1970: The excretory systems and the marginal hooks as a basis for the systematics of Gyrodactylus (Trematoda, Monogenea). Ark. Zool. 2: 1-235.

MALMBERG G. 1993: Gyrodactylidae and gyrodactylosis of Salmonidae. Bull. Fr. Pêche Piscic. 328: 5-46.

MATĚJUSOVÁ I., GELNAR M., VERNEAU O., CUNNINGHAM C.O., LITTLEWOOD D.T.J. 2003: Molecular phylogenetic analysis of the genus Gyrodactylus (Platyhelminthes: Monogenea) inferred from rDNA ITS region: subgenera versus species groups. Parasitology 127: 603611.

MO T.A. 1991a: Seasonal variations of opisthaptoral hard parts of Gyrodactylus salaris Malmberg, 1957 (Monogenea, Gyrodactylidae) on parr of Atlantic salmon Salmo salar L. in the river Batnfjordselva, Norway. Syst. Parasitol. 19: 231-240.

MO T.A. 1991b: Variations of opisthaptoral hard parts of Gyrodactylus salaris Malmberg, 1957 (Monogenea, Gyrodactylidae) on rainbow trout Oncorhynchus mykiss (Walbaum, 1792) in a fish farm, with comments on the spreading of the parasite in south-eastern Norway. Syst. Parasitol. 20: 1-9.

MO T.A. 1991c: Variations of opisthaptoral hard parts of Gyrodactylus salaris Malmberg, 1957 (Monogenea, Gyrodactylidae) on parr of Atlantic salmon Salmo salar L. in laboratory experiments. Syst. Parasitol. 20: 11-19.

MO T.A. 1994: Status of Gyrodactylus salaris problems and research in Norway. In: A.W. Pike and J.W. Lewis (Eds.), Parasitic Diseases of Fish. Samara Publishing, Dyfed, UK, pp. $43-58$.

MO T.A., APPLEBY C. 1990: A special technique for studying haptoral sclerites of monogeneans. Syst. Parasitol. 17: 103-108.

MO T.A., NORHEIM K., HELLESNES I. 2004: The surveillance and control programme for Gyrodactylus salaris in Atlantic salmon and rainbow trout in Norway. Norsk Vet. Tidsskr. 3: 157-163. (In Norwegian, English summary.)

REUTER M. 1987: Immunocytochemical demonstration of serotonin and neuropeptides in the nervous system of Gyrodactylus salaris (Monogenea). Acta Zool. 68: 187193.

SHINN A.P., GIBSON D.I., SOMMERVILLE C. 1993: An SEM study of the haptoral sclerites of the genus Gyrodactylus Nordmann, 1832 (Monogenea) following extraction by digestion and sonication techniques. Syst. Parasitol. 25: 135-144.

SHINN A.P., GIBSON D.I., SOMMERVILLE C. 1997: Argentophilic structures as a diagnostic criterion for the discrimination of species of the genus Gyrodactylus von Nordmann (Monogenea). Syst. Parasitol. 37: 47-57.

SHINN A.P., GIBSON D.I., SOMMERVILLE C. 1998a: Chaetotaxy of members of the Gyrodactylidae (Monogenea), with comments upon their systematic relationships with the Monopisthocotylea and Polyopisthocotylea. Syst. Parasitol. 39: 81-94.

SHINN A.P., GIBSON D.I., SOMMERVILLE C. 2001: Morphometric discrimination of Gyrodactylus salaris Malmberg (Monogenea) from species of Gyrodactylus parasitis- 
ing British salmonids using novel parameters. J. Fish Dis. 24: 83-97.

SHINN A.P., HANSEN H., OLSTAD K., BACHMANN L., BAKKE T.A. 2004: The use of morphometric characters to discriminate specimens of laboratory-reared and wild populations of Gyrodactylus salaris and G. thymalli (Monogenea). Folia Parasitol. 51: 239-252.

SHINN A.P., KAY J.W., SOMMERVILLE C. 2000: The use of statistical classifiers for the discrimination of species of the genus Gyrodactylus (Monogenea) parasitizing salmonids. Parasitology 120: 261-269.

SHINN A.P., SOMMERVILLE C., GIBSON D.I. 1995: Distribution and characterization of species of Gyrodactylus Nordmann, 1832 (Monogenea) parasitizing salmonids in UK, and their discrimination from G. salaris Malmberg, 1957. J. Nat. Hist. 29: 1383-1402.

SHINN A.P., SOMMERVILLE C., GIBSON D.I. 1998b: The application of chaetotaxy in the discrimination of Gyrodactylus salaris Malmberg, 1957 (Gyrodactylidae: Monogenea) from species of the genus parasitizing British salmonids. Int. J. Parasitol. 28: 805-814.

SOLENG A., BAKKE T.A. 2001: The susceptibility of grayling, Thymallus thymallus to experimental infections with the monogenean Gyrodactylus salaris. Int. J. Parasitol. 31: 793-797.
SOLENG A., BAKKE T.A., HANSEN L.P. 1998: Potential for dispersal of Gyrodactylus salaris (Platyhelminthes, Monogenea) by sea-running stages of the Atlantic salmon (Salmo salar): field and laboratory studies. Can. J. Fish. Aquat. Sci. 55: 507-514.

STERUD E., MO T.A., COLLINS C.M., CUNNINGHAM C.O. 2002: The use of host specificity, pathogenicity, and molecular markers to differentiate between Gyrodactylus salaris Malmberg, 1957 and G. thymalli Žitňan, 1960 (Monogenea: Gyrodactylidae). Parasitology 124: 203-213.

TINSLEY R.C. 1978: Oviposition, hatching and the oncomiracidium of Eupolystoma anterorchis (Monogenoidea). Parasitology 77: 121-132.

WATSON N.A., ROHDE K. 1994: Two new sensory receptors in Gyrodactylus sp. (Platyhelminthes, Monogenea, Monopisthocotylea). Parasitol. Res. 80: 442-445.

ZIETARA M.S., LUMME J. 2002: Speciation by host switch and adaptive radiation in a fish parasite genus Gyrodactylus (Monogenea, Gyrodactylidae). Evolution 56: 2445-2458.

ŽITŇAN R. 1960: Gyrodactylus thymalli sp. nov. from the fins of the grayling (Thymallus thymallus L.). Helminthologia 2: 266-269.

Accepted 12 May 2004 